\title{
Comparación in vitro de la microfiltración corono-apical del Enterococcus faecalis con tres diferentes técnicas de obturación: lateral, vertical y de vástago, en premolares unirradiculares
}

\author{
In vitro comparison of corono-apical microleakage of \\ Enterococcus faecalis using three different filling techniques: \\ lateral, vertical and gutta-percha carrier-based, in single-root \\ premolars
}

Recibido: 2018//03/15. Aceptado: 2018/05/02. Publicado: 2018/09/01

\section{Dora Luz Arellano Colorado ${ }^{1}$ Juan D. Mosquera Bolaños ${ }^{2}$ Nicolás Castrillón Sarria ${ }^{3}$}

1 Universidad San Francisco de Quito, Colegio de Ciencias de la Salud, Escuela de Odontología, Clínica Odontológica, Campus Cumbaya', oficina CO 106, casilla postal 17-1200-841. Quito-Ecuador.

Correo electrónico: doraluz83@hotmail.com

2 Universidad San Francisco de Quito, Colegio de Ciencias Biológicas y Ambientales, Instituto de Microbiología, Campus Cumbaya', oficina EE 105, casilla postal 17-1200-841. Quito-Ecuador.

Correo electrónico: juanDBZGT@hotmail.es

3 Universidad San Francisco de Quito, Colegio de Ciencias de la Salud, Escuela de Odontología, Clínica Odontológica, Campus Cumbaya', oficina CO 106, casilla postal 17-1200-841. Quito-Ecuador.

Correo electrónico: nicasa24@gmail.com 


\section{Resumen}

El objetivo de este estudio fue comparar la microfiltración del Enterococcus faecalis en tres técnicas de obturación: condensación lateral, vertical y con vástago de gutapercha. Cuarenta premolares unirradiculares fueron decoronados e instrumentados hasta la Reciproc R50.

Se usó un modelo modificado de cámaras divididas de Torabinejad donde el E. faecalis se colocó en la cámara superior y posteriormente debía pasar hacia la cámara inferior únicamente a través del conducto obturado. La prueba de Kruskal-Wallis mostró que el grupo de obturación con vástago y obturación vertical fueron estadísticamente superiores al grupo de obturación lateral. No se encontró diferencias estadísticamente significativas entre la obturación lateral y el control positivo, ni tampoco entre la obturación con vástago y la obturación vertical ( $p$ > 0.05). En conclusión, la obturación con vástago de gutapercha mostró mayor resistencia a la filtración del E. Faecalis, pero no fue estadísticamente superior a la obturación vertical de onda continua.

Palabras clave: Endodoncia, obturación endodóncica, técnicas de obturación, filtración bacteriana, Enterococcus faecalis, gutapercha, GuttaCore, Chromocult

\section{Abstract}

The purpose of this study was to compare leakage of Enterococcus faecalis in three filling techniques: lateral condensation, vertical condensation and gutta-percha carrier-based obturation. Forty single-root premolars were decoronated and prepared until Reciproc R50.

A modified Torabinejad model was used consisting of a split chamber where E. faecalis was placed in the upper chamber could reach the lower chamber only through the filled canal. The Kruskal-Wallis test showed that corecarrier gutta-percha obturation and vertical obturation groups were statistically superior to lateral obturation group. No statistically significant difference was found between the lateral obturation and positive control, nor between core-carrier technique and vertical obturation ( $p>0.05$ ). In conclusion, core-carrier gutta-percha obturation group showed greater resistance to filtration of E. faecalis but it was not statistically superior to vertical condensation group.

Keywords: Endodontic, endodontic filling, Obturation technique, bacteria leakage, Enterococcus faecalis, guttapercha, GuttaCore, Chromocult 


\section{Introducción}

Los objetivos del tratamiento de endodoncia consisten en limpiar, preparar y rellenar el sistema de conductos radiculares de manera apropiada. Pero su éxito se verá comprometido si la obturación no se realiza correctamente $\mathbf{1 , 2 , 3 , 4}^{\mathbf{2}}$.

Según Schilder, el objetivo de la obturación es lograr un relleno homogéneo y tridimensional del conducto radicular y de todos sus conductos accesorios, ya que pequeños espacios permiten el paso de bacterias y de productos de degradación tisular entre el conducto radicular y el tejido periodontal $\mathbf{2 , 5 , 6}$.

Existe una gran cantidad de evidencia científica que indica que los microorganismos son los principales causantes del fallo del tratamiento de endodoncia, sea por su persistencia o la aparición de una lesión inflamatoria perirradicular después del tratamiento $\mathbf{7 , 8}$.

Técnicas de cultivos microbiológicos han sido utilizados para investigar la microbiota asociada a infecciones endodóncicas, y han revelado que el Enterococcus faecalis es la especie que más se encuentra en infecciones persistentes o aquellas asociadas al fracaso del tratamiento endodóncico8. Los métodos usados para eliminar estos microorganismos son la instrumentación complementada con irrigantes y su posterior activación, una adecuada obturación y finalmente una restauración coronal ${ }^{3}$.

El material usado para la obturación radicular es uno de los determinantes críticos para el éxito o el fracaso del tratamiento endodóncico ${ }^{1}$.

Muchas técnicas han sido propuestas para mejorar la buena adaptación de los materiales de obturación en el espacio radicular. Estos incluyen métodos en base a gutapercha termoplastificada, la compactación lateral de gutapercha en frío y actualmente el uso del cono único de gutapercha 6.
La técnica de compactación lateral es el método de obturación más común y aceptado6. Pero existen nuevas técnicas de obturación que usan gutapercha reblandecida para mejorar el relleno de todo el espacio del conducto y de los istmos4. Brothman, demostró que la compactación vertical con gutapercha caliente duplicó la obturación del número de conductos laterales, en relación con la técnica de compactación lateral 5.

Existen en el mercado productos de obturación en vástagos termoplásticos como son: Thermafil Plus (Dentsply), RealSeal1 (SybronEndo) GuttaMaster (VDW), y actualmente GuttaCore (Dentsply) que es el único sistema de vástago que posee un núcleo de gutapercha rígida entrecruzada, que sirve como transportador para el recubrimiento de gutapercha en fase $a{ }^{9}$.

El objetivo de este estudio fue comparar in vitro el grado de microfiltración corono apical del Enterococcus faecalis en dientes premolares humanos unirradiculares entre diferentes técnicas de obturación: lateral en frío, vertical de onda continúa de calor y gutapercha termoplastificada con vástago de gutapercha termoestable.

\section{Métodos}

Este estudio de tipo comparativo, descriptivo y experimental in vitro analizó 40 dientes premolares humanos unirradiculares, los cuales se almacenaron en suero fisiológico por tres meses hasta iniciar el estudio. Los criterios de inclusión fueron dientes sin tratamiento endodóncico previo, radiográficamente permeables, con ápice maduro y grado de curvatura de Schneider máximo de 200. Se estandarizaron las raíces a una longitud de 16 $\mathrm{mm}$ utilizando una cortadora de precisión y se realizó patencia con una lima K\#10. Se estableció la longitud de trabajo a menos $0,5 \mathrm{~mm}$ de la longitud total con la lima Flexofile \#15 y se estandarizó la instrumentación radicular hasta la 
lima Reciproc R50 usando movimientos de picoteo lento hacia adentro y afuera sin exceder más $3 \mathrm{~mm}$ de profundidad y con ligera presión apical. Después de 3 movimientos de picoteos se retiró el instrumento, se irrigó con $\mathrm{NaOCl}$ 5,25\% y se continuó con la dinámica de instrumentación hasta llegar a la longitud de trabajo10. Se realizó el protocolo de irrigación final acompañado de activación ultrasónica por un minuto con cada irrigante: $5 \mathrm{~mL}$ de $\mathrm{NaOCl}$ al 5,25\%, $5 \mathrm{~mL}$ de suero fisiológico y $5 \mathrm{~mL}$ de EDTA al 17\%. (Eufar, Colombia).

Las raíces se dividieron de manera aleatoria en tres grupo (A, B, C) de 10 raíces cada una correspondientes a las técnicas de obturación evaluadas y dos grupos control de 5 raíces cada una (D,E). Grupo A: Obturación lateral en frío: Cono de Gutapercha No.50.02 y conos accesorios A y B. Grupo B: Obturación vertical de onda continua de calor y gutapercha termoplastificada: Conos Reciproc R50 y gutapercha en barra. Grupo C: Obturación con vástago de gutapercha termoestable: Vástago de gutapercha GuttaCore No.50. Grupo D: Control positivo: Diente sin obturación con BHI contaminado con E. Faecalis. Grupo E: Control negativo: Diente sin obturación con BHI sin contaminación de E. Faecalis. Se usó TopSeal. como cemento sellador para el grupo A,

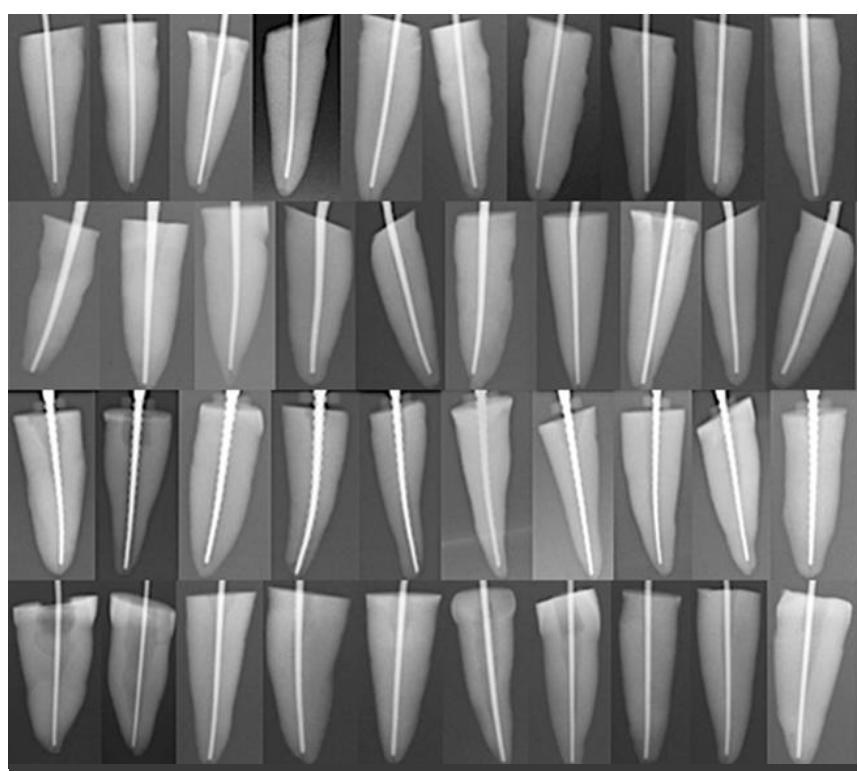

FIGURA 1. CONOMETRÍAS RADIOGRÁFICAS
B y C. Finalmente se tomó conometrías usando el cono maestro o el verificador dependiendo de la técnica de obturación (Fig. 1).

Los dientes se almacenaron en frascos estériles hasta armar las cámaras. Para fabricar las cámaras se usó un modelo modificado de cámaras divididas de Torabinejad y col. ${ }^{11}$ usando un tubo decentrífuga Falcon de $15 \mathrm{~mL}$; donde el $\mathrm{BHI}$ contaminado de E. faecalis se colocó en la cámara superior y el Caldo de Enteroccoccus Chromocult que es el reactivo identificador de la bacteria se situó en la cámara inferior. La raíz obturada se colocó en el orificio inferior de la cámara superior sobresaliendo $8 \mathrm{~mm}$ рага que la la punta de la raíz entrara en contacto con el caldo Chromocult (Fig. 2). Todo con el objetivo de que la bacteria pase netamente a través de la obturación hasta hacer contacto con el reactivo y provoque su cambio de coloración.

Una vez fabricadas las cámaras se rotularon y se colocaron en frascos estériles para autoclavarlos junto a las raíces por $20 \mathrm{~min}$ a $121^{\circ} \mathrm{C} \pm 2$.

Previo a la obturación de las raíces se estandarizó la cantidad de cemento Top Seal en 0,2g para cada muestra usando una balanza de precisión y

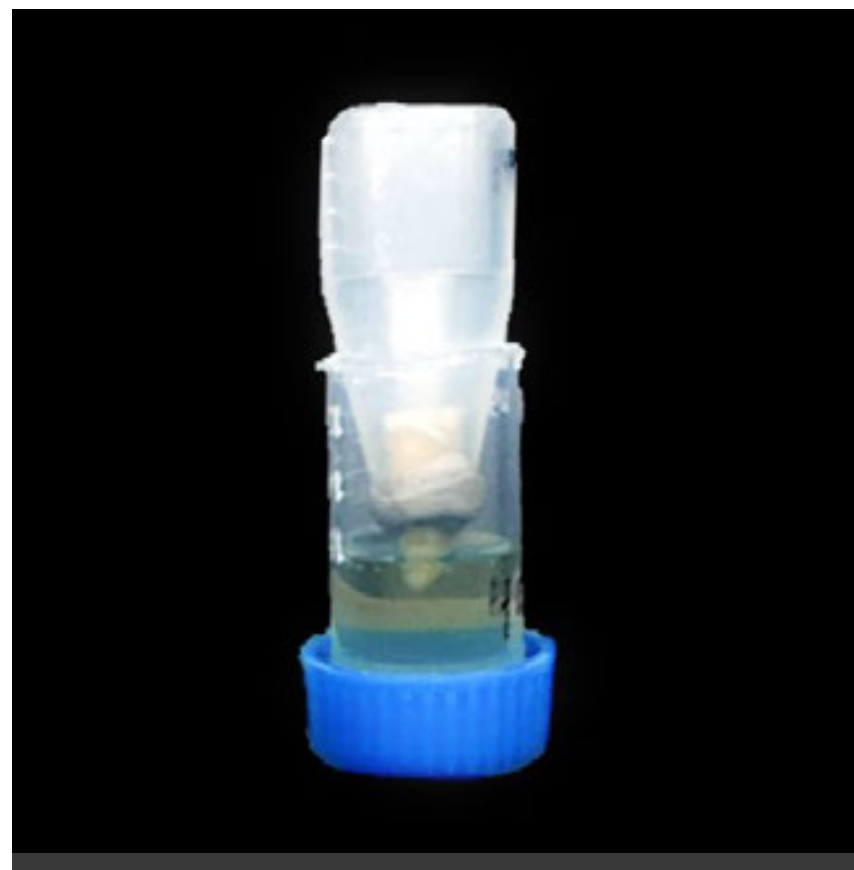

FIGURA 2. ÁPICE EN CONTACTO CON REACTIVO 
se desinfectaron los conos principales y accesorios en $\mathrm{NaOCl}$ al 5,25\% por 5 minutos. Todo el proceso de obturación radicular fue realizado por un sólo operador con guantes quirúrgicos estériles y se llevó a cabo dentro de la cámara de flujo laminar con activación previa de luz UV por 15 minutos. Se realizó la obturación de las raíces de los grupos A, B y C siguiendo las indicaciones de cada técnica. Los grupos D y E no fueron obturados por ser grupos control. Por último, se almacenó en frascos estériles.

Para la contaminación del BHI se utilizó la cepa ATCC 29212, la cual fue cultivada en agar nutritivo y se dejó en la incubadora a $36,5^{\circ} \mathrm{C} \pm 0,5$ hasta el momento de la inoculación. Se preparó $250 \mathrm{~mL}$ de BHI y se inoculó con 5 colonias de $\mathrm{E}$. Faecalis (Fig. 3). Рara estandarizar el número promedio de bacterias de cada muestra, se realizó la técnica de contaje directo de bacterias viables al microscopio usando la cámara Petroff Hausser, y teniendo como promedio 4,456 x108 bacterias en $2 \mathrm{~mL}$ de $\mathrm{BHI}$ que fue lo que se usó en cada muestra. Posteriormente se preparó $250 \mathrm{~mL}$ de caldo de Enterococcus Chromocult.

El montaje de cámaras se realizó dentro de la cámara de flujo laminar previo uso de rayos UV por 15 minutos y con el uso de guantes quirúrgicos estériles. Se selló la interfase entre el diente y la cámara superior con resina epóxica dejándola fraguar por 24 horas y almacenándola en frascos estériles. Luego de este tiempo se selló la unión entre la rosca y la tapa de la cámara inferior del tubo Falcon con cinta teflón de 1/2".

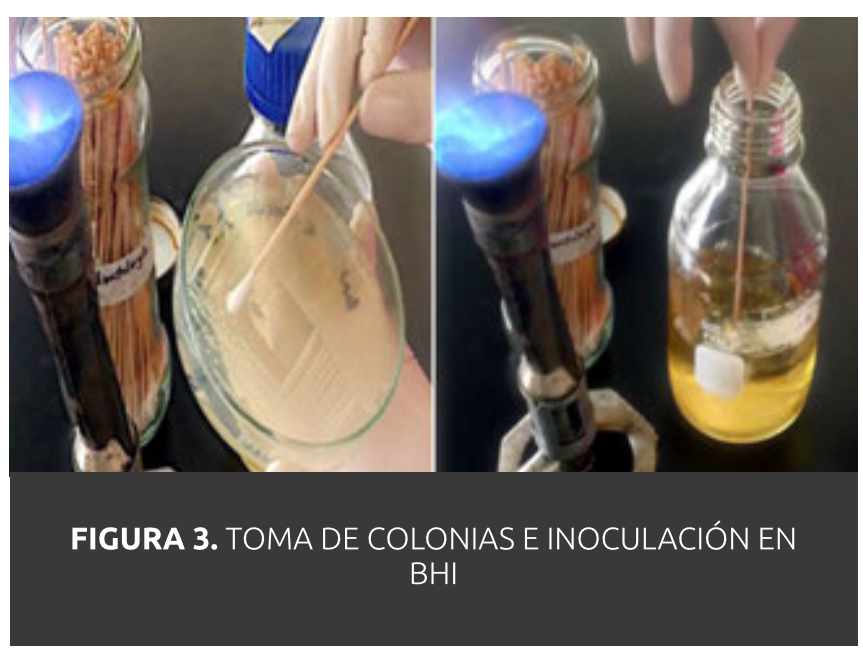

Con una jeringa desechable estéril de $3 \mathrm{~mL}$ se colocó 2,5 mL de caldo Chromocult en la cámara inferior y se controló que el ápice entre en contacto con el caldo Chromocult. Se unieron las cámaras superior e inferior sellando su unión con cinta de plástico biodegradable Parafilm y con una nueva jeringa estéril de $3 \mathrm{~mL}$ se colocó $2 \mathrm{~mL}$ de $\mathrm{BHI}$ inoculado con E. Faecalis en la cámara superior y se selló su apertura con Parafilm.

Se organizaron las muestras en gradillas fabricadas con espuma flex y se las ubicó en la incubadora a temperatura de $36,5^{\circ} \mathrm{C} \pm 0,5$ durante todo el tiempo de observación.

El BHI contaminado con E. faecalis de la cámara superior fue reemplazado cada 4 días por un nuevo caldo contaminado con el objetivo de mantener a las bacterias viables.

Todas las cámaras inferiores fueron observadas a diario por 22 días para ver en qué momento se producía el cambio de color del caldo Chromocult de amarillo a verde, como evidencia de la filtración bacteriana a través de la obturación de las raíces (Fig. 4).

Los datos recopilados fueron almacenados en una hoja de cálculo y se analizaron

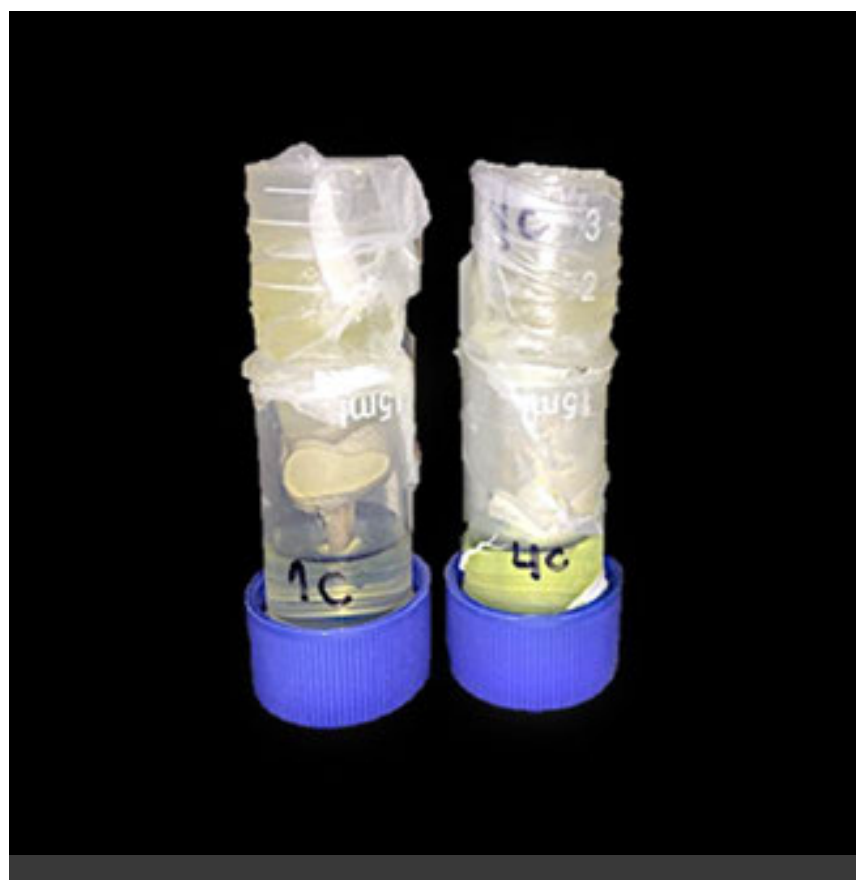

FIGURA 4. EVIDENCIA DE FILTRACIÓN BACTERIANA 
estadísticamente mediante el programa IBM SPSS Statistics 22. Se compararon los valores promedio de todas las muestras y de cada grupo de obturación. Debido a que los datos no se distribuyeron normalmente (prueba de ShapiroWilk) se sometieron a la prueba no paramétrica de Kruskal Wallis y la prueba de parejas para demostrar si existía diferencias significativas entre los grupos. El nivel de significancia se estableció en $p<0,05$

\section{Resultados}

La Tabla 1 muestra el valor de las medias de todas las muestras del estudio (10,14 días) y el valor de la asimetría $(0,239)$ que por ser un valor positivo nos indicaba de manera anticipada la no normalidad en los resultados.

\begin{tabular}{|l|r|}
\hline Descriptivos generales & Valor \\
\hline N Válidos & 35 \\
\hline N Perdidos & 5 \\
\hline Media & 10,14 \\
\hline Error estándar de la media & 1,125 \\
\hline Mediana & 9,00 \\
\hline Moda & 4 \\
\hline Desviación estándar & 6,656 \\
\hline Varianza & 44,303 \\
\hline Rango & 21 \\
\hline Mínimo & 1 \\
\hline Máximo & 22 \\
\hline Asimetría & 0,239 \\
\hline Curtosis & $-1,098$ \\
\hline
\end{tabular}

TABLA 1. ESTADÍSTICA DESCRIPTIVA GENERAL

La tabla 2 muestra las medias de días de filtración de cada grupo de obturación, mostrando al grupo de control positivo y de obturación lateral con la filtración más rápida con 1 y 5,1 días respectivamente, seguido por el grupo de obturación vertical con una media de 13,20 días y por último la obturación con vástago presentó una media de 16,7 días siendo la obturación que más tardó en filtrar.

En la Tabla 3 se puede observar los valores de significancia $(p>0,05)$ mostrando que no hay diferencia estadísticamente significativa entre el control positivo y la condensación lateral y entre el grupo de obturación con vástago y la condensación vertical.

\begin{tabular}{|l|l|}
\hline GRUPOS & $p$ \\
\hline Control positivo - Obturación lateral & 1,000 \\
\hline Control positivo - Obturación vertical & 0,002 \\
\hline Control positivo - Obturación con vástago & 0,000 \\
\hline Obturación lateral - Obturación vertical & 0,044 \\
\hline Obturación lateral - Obturación con vástago & 0,002 \\
\hline Obturación vertical - Obturación con vástago & 1,000 \\
\hline
\end{tabular}

TABLA 3. PRUEBAS DE COMPARACIÓN DE PAREJAS

En la tabla 4 se observa que la obturación lateral empieza a filtrar en T4 e iguala al control positivo en T7; en la obturación vertical empieza a filtrar en T9 e iguala al control positivo en T16; en la obturación con vástago empieza la filtración en T12 y en T21 iguala a control positivo; el control positivo filtra siempre y el control negativo no filtró.

\section{Discusión}

Las técnicas de obturación endodóncica han ido mejorando con el transcurso del tiempo gracias a la fabricación de nuevas tecnologías que permiten mejorar el sellado del conducto radicular. En este estudio in vitro se comparó la microfiltración entre tres técnicas de obturación que actualmente son las más empleadas, en especial la obturación por condensación lateral que es una técnica sencilla y económica en 


\begin{tabular}{|l|c|r|r|c|c|}
\hline \multicolumn{3}{|l}{$\begin{array}{l}\text { Descriptivos específicos } \\
\text { Tipo de Obturaciór }\end{array}$} & Media & Desviación estánda & Máx. \\
\hline Lateral & 10 & 5,10 & 1,449 & 4 & 7 \\
\hline Vertical & 10 & 13,20 & 3,425 & 9 & 16 \\
\hline Vástago & 10 & 16,70 & 4,547 & 12 & 22 \\
\hline Positivo & 5 & 1,00 & 0,000 & 1 & 1 \\
\hline Total & 35 & 10,14 & 6,656 & 1 & 22 \\
\hline
\end{tabular}

\section{TABLA 2. ESTADÍSTICA DESCRIPTIVA ESPECÍFICA DE CADA TIPO DE OBTURACIÓN}

comparación con las técnicas de condensación vertical y de obturación con GuttaCore que son más actuales y requieren del uso de ciertos equipos pero que en sí prometen mejores resultados para que sean tomados como una alternativa eficaz.

Según Martínez y col. existen muchos factores que pueden influir en la microfiltración, tales como la técnica de obturación, propiedades físicas y químicas del cemento sellador, la anatomía radicular, la habilidad del operador, entre otras ${ }^{12}$. Рara este estudio se usó un modelo modificado de cámaras divididas de Torabinejad y col. y que posteriormente fue también usado por Shipper y col. ${ }^{13}$.

Se usó el Enterococcus Faecalis; que es una bacteria clínicamente relevante, ya que es predominante en fracasos endodóncicos y es común encontrarla en el conducto radicular junto a otras bacterias anaerobias facultativas ${ }^{13}$.

Para el reconocimiento del Enterococcus faecalis se usó el caldo de Enterococcus Chromocult debido a su alta especificidad frente a esta bacteria (casi 98\%), y por la presencia de azida
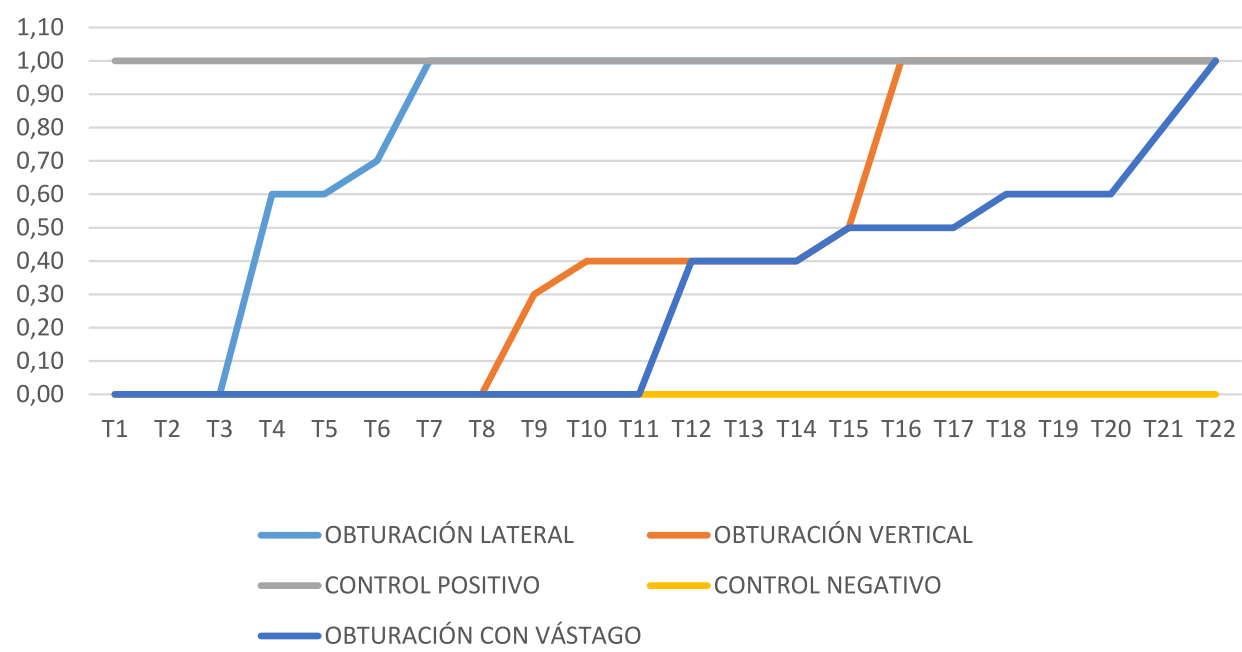
sódica que inhibe el crecimiento de otros tipos de bacterias, evitando falsos resultados. Además, por su fácil detección cromogénica de amarillo a verde ${ }^{15}$.

Se usó un cemento sellador con base en resina epóxica como Top Seal. Según Colán y García este tipo de cemento presenta menor grado de filtración y su sellado apical es superior que otros tipos de cementos16. De Sousa y col. refieren que se forman enlaces covalentes entre el colágeno de la dentina y el cemento, produciendo una buena adhesión, siendo un cemento ideal en este estudio ${ }^{17}$.

Castañeda y col. comparó el grado de filtración apical usando azul de metileno entre la técnica de obturación lateral en frío y la técnica vertical, concluyendo que la técnica de obturación vertical produce un mejor sellado apical14. Resultados similares se encontró en el estudio de Ponce y col. donde la condensación lateral en frío filtró en mayor cantidad que la técnica de condensación vertical, posiblemente debido al exceso de cemento que posteriormente se contrae y se diluye causando así la mayor cantidad de filtración, por lo que los estudios de microfiltración deben ser realizados y evaluados idealmente en un lapso de al menos 15 días o más ${ }^{18}$.

Gençoglu N y col. en el 2007 investigaron la filtración apical con 6 diferentes técnicas de obturación radicular utilizando un medidor de fluido computarizado, y el resultado que obtuvo fue muy similar al de este estudio, ya que el análisis estadístico indicó que las técnicas con Thermafil, Soft Core, Quick-Fill y System B mostraron menor filtración en comparación con el Microseal y la técnica de condensación lateral; al igual que no habían diferencias significativas entre las técnicas de vástago y System $B$, ni tampoco entre la técnica de condensación lateral y el Microseal. Planteándose que la proporción reducida del cemento sellador en comparación con la gutapercha puede mejorar el sellado, debido a que los cementos son materiales solubles que se contraen en mayor o menor grado dependiendo de su tipo, produciendo vías que permiten la filtración. Por lo anterior se puede concluir que las técnicas de vástago al usar muy poco cemento sellador y una mayor cantidad de gutapercha se distribuye de manera homogénea creando una obturación lo más tridimensional posible del sistema de conductos radiculares ${ }^{19}$.

Similares resultados obtuvieron Tomer y col. en el 2016 observando la penetración del azul de metileno para determinar la microfiltración apical entre las técnicas de obturación: lateral, cono único, Obtura, Calamus y Thermafil con diferentes limas de instrumentación. Donde el Calamus y el Thermafil mostraron una diferencia significativa en comparación a los otros grupos y por lo tanto presentaron menor filtración que las otras técnicas de obturación $\mathbf{2 0}$.

A pesar de que en este estudio no existió diferencia significativa entre la técnica de obturación con vástago y la de condensación vertical se puede evidenciar que la técnica de obturación con vástago produjo una microfiltración más lenta comparado con las otras técnicas, posiblemente porque la técnica de condensación lateral es en frío y la obturación vertical y de vástago de gutapercha son en calor. La distribución del calor en la gutapercha como lo indicó Briseño y col. en el 2015 en su estudio mostraron que la gutapercha es un pobre conductor del calor y la distribución de la misma es inconsistente y no depende ni de su conicidad ni del tamaño; siendo así que una temperatura de $65^{\circ} \mathrm{C}$ o mayor no se pudo medir más allá de 2,1 $\mathrm{mm}$ del cono de gutapercha en el "punto de unión" con el portador de calor, por lo tanto al no deformarse plásticamente de manera completa compromete la adaptación apical y la calidad de sellado de la gutapercha. Contrario a lo que pasa con los sistemas de vástago dentro del horno, donde el calor se distribuye uniformemente por todo el vástago y no sólo en la parte de contacto 
con el portador como pasa en la técnica de condensación vertical ${ }^{21}$.

Cabe recalcar que un aumento mayor de $10^{\circ} \mathrm{C}$ en la superficie radicular puede provocar daño periodontal y posterior reabsorción y anquilosis de la misma. Las técnicas de obturación que presentan calor tales como la obturación vertical y de vástago no producen daño, ya que la gutapercha usada en el sistema inyectable alcanza una temperatura de 160 a $200^{\circ} \mathrm{C}$, pero al ser extruida llega entre los $62-65^{\circ} \mathrm{C}$, de igual manera los condensadores eléctricos con portadores de calor llegan alcanzar una temperatura de $200^{\circ} \mathrm{C}$, pero al entrar en contacto con la gutapercha y el cemento sellador solo consiguen incrementos en la temperatura del ligamento de $7,5^{\circ} \mathrm{C}$. De acuerdo también con resultados de investigaciones sobre el aumento de temperatura en la superficie externa de la raíz durante el uso de obturadores éste llega sólo a un aumento promedio de $3,87^{\circ} \mathrm{C}$, debido a que su gutapercha de tipo a no requiere mayor cantidad de temperatura para reblandecerse $\mathbf{2 2}$.

Se demostró en este estudio que el sistema de vástago produjo una menor microfiltración debido al adecuado sellado radicular que produce, sin embargo existió una tendencia de extrusión del material a través del ápice en la mayoría de las muestras, siendo una gran desventaja de este método de obturación, misma observación que tuvo Giudice en su estudio del 2011 al compararlo con los sistemas de condensación lateral y otros sistemas de gutapercha caliente, posiblemente debido a la rápida inserción del vástago en el conducto ${ }^{22}$.

Finalmente, aunque se encuentre un método y materiales de obturación confiables e ideales, es importante garantizar el mismo complementándolo con el sellado coronal por medio de la rehabilitación ${ }^{3}$.

\section{Conclusiones}

- La técnica de obturación con vástago de gutapercha presentó menor tiempo de microfiltración del E. faecalis en comparación con los sistemas de obturación lateral en frío y de condensación vertical con onda continua de calor, pero estadísticamente la técnica de obturación con GuttaCore no fue significativamente superior a la técnica de condensación vertical de onda continua.

- La técnica de obturación lateral en frío fue la primera en presentar microfiltración y rápidamente igualó al grupo control positivo, no encontrándose una diferencia estadísticamente significativa entre ellos.

- Los tiempos promedio de filtración de cada grupo de obturación fueron los siguientes: El grupo de condensación lateral: 5,1 días, el grupo de condensación vertical: 13,2 días y el grupo de obturación de vástago de gutapercha: 16,7 días.

\section{Referencias bibliográficas}

1. Hammad, M; Qualtrough, A y Silikas, N. Evaluation of Root Canal Obturation: A Three-dimensional In Vitro Study. Journal of Endodontics.2009; 35(4):541-544.

2. Goldberg, F; Artaza, L.P y De Silvio, A. Effectiveness of Different Obturation Techniques in the Filling of Simulated Lateral Canals. Journal of Endodontics.2001; 27(5):362-364.

3. Prado, M; Simao, R.A y Gomes, B.P. A microleakage study of gutta-percha/AH Plus and Resilon/Real self-etch systems after different irrigation protocols. Journal of Applied Oral Science. 2014; 22(3):174179. 
4. Schäfer, E. y Olthoff, G. Effect of three different sealers on the sealing ability of both Thermafil obturators and cold laterally compacted gutta-percha. Journal of Endodontics.2002; 28(9):638-642.

5. Perry, C; Kulild, J.C y Walker, M.P. Comparison of Warm Vertical Compaction Protocols to Obturate Artificially Created Defects in the Apical One-third. Journal of Endodontics. 2013; 39(9):1176-1178.

6. Schäfer, E; Kester, M. y Bürklein, S. Percentage of Gutta-percha-filled areas in canals instrumented with nickel-titanium systems and obtrude with matching single cones. Journal of Endodontics. 2013; 39(7):924-928.

7. Hedge, V y Arora, S. Effect of advanced irrigation protocols on self-expanding Smart-Seal obturation system: A scanning electron microscopic push-out bond strength study. Contemporary Cinical Dentistry. 2015; 6(1):26-30.

8. Zoletti, G.O; Siqueira, J.F. y Santos, K.R.N. Identification of Enterococcus faecalis in root-filled teeth with or without perirradicular lesion by culture dependent and - independent approaches. Journal of Endodontics.2006; 32(8):722-726.

9. Whitten, R. y Leviton, M. The effect of canal preparation on fill length in straight root canals obdurate with GuttaCore. Journal of Endodontics.2015; 41(2):155158.

10. VDW. Instrucciones de uso BeeFill 2in1. Estados Unidos; 2014
11. Torabinejad, M; Ung, Borasmy y Kettering, J. In Vitro Bacterial Penetration of Coronally Unsealed Endodontically Treated Teeth. Journal of Endodontics.1990; 16(12): 566-569.

12. Martínez, P; Gómez, M; Felií, K; Alcántar, R y Fuentealba, P. Estudio comparativo de microfiltración apical entre tres técnicas de obturación radicular: Calamus, Guttacore y Guttafusion. Resumen del Congreso de la Sociedad Endodoncia Concepción. 2017; 89.

13. Shipper, G; Ørstavik, D; Batista, F y Trope, M. An Evaluation of Microbial Leakage in Roots Filled with a Thermoplastic Synthetic Polymer-Based Root Canal Filling Material (Epsilon). Journal of Endodontic.2004; 30(5):342-347.

14. Castañeda, A; Hernández, S; Robles, J; Velázquez, J; Benitez, C y Barajas, L. Estudio comparativo de filtración apical entre las técnicas de obturación lateral y vertical en endodoncia. Revista Oral. 2010; 11(33): 573-576.

15. Miranda, J; Franco, C; Vásquez, B; Fente, C; Barros-Velázquez; J y Cepeda, A. Evaluation of Chromocult enterococci agar for the isolation and selective enumeration of Enterococcus spp in broiler. Letters in Applied Microbiology. 2005; 41: 153-156.

16. Colán, P. y García, C. Microfiltración apical in vitro de tres cementos utilizados en la obturación de conductos radiculares. Rev Estomatol Herediana. 2008; 18(1):9-15. 
17. De Sousa, B; Koury, J; García, E; Méndez, C y Antúnez, M. Interfase TopSeal-dentina en relación con dos técnicas de obturación: Condensación lateral y técnica termoplastificada/ termoreblandecida. Estudio de microscopía electrónica de barrido. Universitas Odontológica. 2010; 29(62):39-44.

18. Ponce, A; Izquierdo, J.C. Sandoval, F. y De Los Reyes, J.C. Estudio comparativo de filtración apical entre la técnica de compactación lateral en frío y técnica de obturación con System B. Revista Odontológica Mexicana.2005; 9(2):65-72.

19. Gençoglu N1, Oruçoglu $H$, Helvacioglu D. Apical leakage of different gutta-percha Techniques: Thermafil, Js Quick-Fill, Soft Core, Microseal, System B and Lateral Condensation with a Computerized Fluid Filtration Meter. European Journal of Dentistry. 2007; 1(2):97-103
20. Tomer, A; Banerjee, S; Bhardwaj, G; Malik, $\mathrm{N}$; Muni, S y Rana, S. Comparative Evaluation of Apical Microleakage of Various Obturation Techniques using Single Cone Gutta-percha, Lateral Condensation, Obtura, Calamus and Thermafil by Dye Penetration Method. International Journal of Oral Care and Research. 2016; 4(1): 4-7.

21. Briseño, B; Gerhard, T; Schürger, D. y Willershausen, B. Thermoplastic properties of Endodontic gutta-percha: A thermographic In Vitro Study. Journal of Endodontics. 2015; 41(1):79-82.

22. Giudice, A. Y Torres, J. Obturación en endodoncia - Nuevos sistemas de obturación: revisión de literatura. Revista Estomatológica Herediana. 2011; 21(3):166-174. 